\title{
FICÇÃO E REALIDADE NAS OBRAS DE DAZAI OSAMU
}

Karen Kazue Kawana

Resumo: Este trabalho faz uma breve incursão na história e conceito de watakushi shôsetsu antes de analisarmos em que medida as obras de Dazai Osamu poderiam ser enquadradas nesse gênero literário. Palavras-chave: Dazai Osamu, Literatura Japonesa, Escrita do Eu, Naturalismo, Realismo

\begin{abstract}
We make a brief incursion into the idea and history of the concept of watakushi shôsetsu before analyzing in which measure the works of Dazai Osamu could be said to belong to this literary genre.
\end{abstract}

Keywords: Dazai Osamu, Japanese Literature, I novel, Naturalism, Realism

Dazai Osamu, cujo nome real é Tsushima Shûji, é considerado um dos grandes escritores japoneses da primeira metade do século XX. Autor de textos nos quais expõe suas misérias e os acontecimentos de seu cotidiano com pinceladas dramáticas, melodramáticas até, provocando repulsa em autores que acreditam que o escritor deveria preservar sua dignidade. Kawabata Yasunari e Shiga Naoya foram alguns dos que criticaram esse aspecto de sua obra.

Autor, também, de obras nostálgicas, da busca de uma infância e de uma terra natal que vivem apenas em sua memória, temas comuns na época se nos lembrarmos de que a primeira metade do século passado foi o da grande urbanização de Tóquio, cidade que atraía as pessoas pelas suas infinitas possibilidades, o lugar onde tudo ocorria e, ao mesmo tempo, tudo poderia ser perdido, a começar pelas raízes. É em busca delas que Dazai parte em uma viagem a Tsugaru, o lugar onde

1. Mestranda do programa de Língua, Literatura e Cultura Japonesa da Universidade de São Paulo. Contato: kawanakk@usp.br 
nasceu, mas que pouco conheceu, e encontra explicações para sua falta de jeito para se relacionar com os outros. No fundo, ele era um homem do campo, rústico, sem refinamentos como seus conterrâneos, alguém que se sente deslocado na capital.

E há as guerras, as vitórias no continente asiático e a grande derrota para os Aliados, a bomba atômica, enfim, um período de perdas que marcou profundamente o espírito de toda uma geração. Como não poderia deixar de acontecer, a guerra aparece como pano de fundo de vários de seus textos: nas notícias ouvidas pelo rádio, nos racionamentos aos quais a população estava submetida, nos bombardeios, nas despedidas dos jovens que partiam para o campo de batalha, coisas que se tornaram rotina nesse período e ficaram registradas em suas obras.

Há também o Dazai divertido, irônico, muitas vezes amargo e ressentido, um pouco neurótico quando se sente perseguido ou condenado pelos membros do bundan, essa sociedade formada por escritores e críticos à qual os jovens aspirantes a literatos sonham em pertencer e, por isso mesmo, procuram agradar.

As obras de Dazai são classificadas como watakushi shôsetsu², gênero popular no período Taishô (1912-1926) e início do período Shôwa (1926-89). Alguns críticos consideram esse um gênero literário tipicamente japonês, enquanto outros discordam e consideram-no apenas fruto de uma ideologia criada e propagada pelo bundan ${ }^{3}$.

O romance ocidental passa a inspirar a criação do romance moderno no Japão a partir do período Meiji (1868-1912). Muitos autores e críticos, influenciados pelas obras de escritores como Zola, Maupassant e Rousseau, passam a pregar uma literatura mais autêntica e verdadeira, fiel à realidade e na qual os sentimentos dos personagens e seus processos internos seriam expressos de forma transparente. No Ocidente, o romance surge junto com a ascensão da burguesia e a valorização da individualidade. Com o enfraquecimento das monarquias e do sistema hierárquico associado a elas e a exaltação dos ideais democráticos, cada um torna-se livre para perseguir seus objetivos, buscar elevação social, enriquecer, tornar-se um artista, etc. No entanto, apesar da maior liberdade, os desejos pessoais frequentemente esbarram nas exigências e valores da sociedade. E são esses conflitos os grandes temas dos romances. Madame Bovary e Anna Karenina, por exemplo, são mulheres que aspiram a mais do que um casamento morno e sonham com amantes apaixonados, condenadas pela sociedade por afrontarem suas convenções, têm fins trágicos.

Os escritores ocidentais das vertentes naturalista e realista do século XIX procuram descrever essas situações com fidelidade, revelam os sentimentos de

2. Também conhecido como shishôsetsu, os dois termos são intercambiáveis.

3. Sobre o Watakushi Shôsetsu: Suzuki, Tomi. Narrating the Self. $1^{\text {a }}$ ed. Stanford: Stanford University Press, 1996. Ver também: Fowler, Edward. The Rhetoric of Confession. 1a ed. Berkeley: University of California Press, 1988. 
seus personagens de modo preciso e desapaixonado, não se imiscuindo ou envolvendo pessoalmente na narrativa. Trata-se de ficções, os personagens e os enredos são criados por seus autores para descrever temas universais de forma objetiva. Qualquer mulher poderia se identificar com as personagens de Flaubert ou Tolstoi e torcer por sua sorte.

Agora, vejamos o caso do Japão. A Revolução Meiji importou a tecnologia e as ideias democráticas do Ocidente, entretanto, os valores feudais e hierárquicos permaneceram e levaram os últimos golpes apenas após a Segunda Guerra. Tratar de conflitos entre sociedade e indivíduo nesse ambiente não era uma empreitada simples, além disso, havia uma censura acirrada, os autores japoneses não tinham a mesma liberdade dos autores ocidentais para escrever sobre temas considerados delicados para a manutenção do status quo.

O naturalismo japonês conservou a ideia de que a literatura deve ser fiel à realidade, também prega que os sentimentos dos personagens deveriam ocupar um papel importante nos textos, mas sem o confronto com a sociedade, seus conflitos tornam-se subjetivos, a realidade e os sentimentos são aqueles retirados das experiências do próprio autor e se exaurem nelas. Assim teria surgido o watakushi shôsetsu, a escrita do eu, que ganha esse nome no início dos anos 20. Seu marco inicial seria o romance Futon, de Tayama Katai, publicado em 1907.

Muitos críticos exaltam o watakushi shôsetsu, pois se trataria de um gênero próprio do Japão e diferente do naturalismo ocidental, enquanto outros apontam sua limitação em relação a este último, afinal, os assuntos se esgotam na vida dos autores, não haveria uma universalização dos temas, mas sua particularização. Assim mesmo, não são poucos aqueles que chegam a afirmar que um texto que não seja baseado em fatos vividos pelo autor não poderia ser considerado "genuíno" e, segundo esse critério, obras fictícias como Madame Bovary e Anna Karenina seriam condenadas como pertencendo a um gênero inferior. Podemos dizer que os aprendizes se voltam contra os feiticeiros.

Por meio do watakushi shôsetsu, os escritores podem se expressar abertamente e, mesmo que os textos não sejam escritos em primeira pessoa, o autor é sempre uma figura identificável. Tirar da vida o material para elaborar um texto literário certamente não é algo restrito ao Japão e inúmeros autores ocidentais utilizaram esse recurso, mas provavelmente em nenhum outro lugar esse tipo de texto transformou-se em gênero literário e virou objeto de estudos, com seguidores e críticos, fato que talvez possa ser explicado pela própria existência do bundan, núcleo literário ao qual a maioria dos escritores e críticos pertencia.

Nas primeiras décadas do século XX, o público japonês preferia obras de cunho mais popular, como romances açucarados e aventuras de enredo palpitante, textos nos moldes do watakushi shôsetsu eram considerados cultos e lidos principalmente pelos membros do próprio bundan. Não raro, os relacionamentos e anedotas 
comuns acabavam nas páginas de algum romance ou conto, o que apenas reforçava a identificação dos narradores e personagens com pessoas e acontecimentos reais.

Alguns críticos como Hirano Ken (1907-78) procuraram estabelecer tipos distintos de watakushi shôsetsu, como o shinkyô shôsetsu, uma narrativa do estado de espírito. Enquanto o watakushi shôsetsu englobaria aqueles textos nos quais os autores narram sua alienação em relação à sociedade e seu sentimento de impotência, o shinkyô shôsetsu seria uma literatura de salvação, de superação da crise e reencontro do equilíbrio. O primeiro seria destrutivo, o segundo, harmônico ${ }^{4}$. Dazai Osamu e Shiga Naoya, respectivamente, são citados como exemplos de cada tipo. Dazai, o escritor das muitas tentativas de suicídio que morre afogado junto com a amante pouco antes de completar 39 anos; Shiga, de caráter tão diverso de Dazai, mais austero e contemplativo, o chamado "Deus do Romance"s. Autores e obras acabam por ser associados a autobiografias ou confissões ${ }^{6}$.

Entretanto, não é possível reduzir a obra de um autor a um tipo de autobiografia, pois mesmo que ela seja baseada em experiências pessoais, ela não é um mero relato ou diário, mas um texto literário e, nele, suas experiências recebem, por assim dizer, uma roupagem diferente e, uma vez publicado, passa a ter uma existência e valor independentes de seu autor. Talvez seja difícil para um biógrafo ignorar as "coincidências" entre episódios narrados e a vida de um escritor, mas é perfeitamente possível estudar um texto sem ultrapassar seu âmbito.

No caso de Dazai, é muito fácil usar seus textos como uma espécie de diário, pois ele emprega episódios de sua vida como ingredientes de suas obras: as várias tentativas de suicídio, as bebedeiras e a vida desregrada ${ }^{7}$. Mas eles constituem apenas uma parte do material de seus textos e não devem ser identificados com uma realidade objetiva.

O que pode ser considerado realidade, ou melhor, verdade em literatura? Em Geijutsu Girai (1944), um pequeno texto no qual Dazai critica a ideia de "arte" como "artifício", ele escreve:

É melhor jogar fora as noções de adereços vagos, o chamado 'artístico'. Viver não é arte. A natureza também não. Seguindo essa lógica, o romance também não é arte. Há uma teoria que afirma que o romance começa a se degradar no momento em que o consideramos arte e eu concordo. A produção literária deve se esforçar para

\footnotetext{
4. Suzuki, 1996.

5. Shiga era conhecido como o "Shôsetsu no Kamisama".

6. Segundo o crítico Koyano Ton, com exceção das obras de fíç̧ão científica, fantasia ou romances históricos, poucas obras literárias não conteriam algum elemento retirado das experiências de um autor. v. Koyano, Ton. Watakushi Shôsetsu Towa. $1^{a}$ ed. Tóquio: Heibonsha, 2009.

7. Por exemplo, a tentativa de suicídio com a primeira esposa, Oyama Hatsuyo é narrada em Ubasute (1938) e seu período internado para se tratar do vício em analgésicos está em Human Lost (1941). O duplo suicídio com Tanabe Shimeko, na qual esta morre, aparece em Dôke no Hana (1935) e Ningen Shikkaku (1948).
} 
ser 'acurada'. Não há nada além disso. Quando um moinho de vento é visto como um demônio, é preciso fazer a descrição de um demônio sem hesitação. Agora, se olharmos para um moinho de vento e não vermos nada além de um moinho de vento, é melhor descrevê-lo como um moinho de vento. Há escritores tolos que, mesmo vendo um moinho de vento, descrevem-no como um demônio por meio de várias técnicas engenhosas facilmente identificáveis, eles têm a intenção de ser românticos, acham isso 'artístico', mas nunca chegarão a lugar algum dessa forma. Não se deve nunca procurar dar ares 'artísticos' a um romance. ${ }^{8}$ (Dazai, 1989, p. 5).

Algo coerente para um autor que detesta a formalidade, a hipocrisia e valoriza a livre expressão dos sentimentos e a espontaneidade mesmo que isso o leve a ser contraditório. O watakushi shôsetsu rejeita ficções, mas basear a realidade em percepções subjetivas acaba por aproximar os textos daquilo de que a teoria diz que eles devem se distanciar em um movimento muito sutil.

Para Dazai, ser "artístico" seria um meio-termo indesejável, ver moinhos e dizer que "sua estatura e forma são comparáveis a de gigantes" é falhar com a realidade. Pela leitura do trecho acima, vemos que ele considerada real, ou seja, verdadeiro, aquilo que é visto e sentido como sendo verdadeiro e é isso que deve ser descrito. Os gigantes que Dom Quixote vê sobre as colinas são tão reais quanto os moinhos de vento de Sancho Pança, nenhum dos dois está errado, pois ambos dizem o que suas percepções dizem que é verdadeiro. Como as percepções são subjetivas, não podemos falar em uma única realidade, mas em múltiplas, cada personagem de uma obra literária deve refletir isso. Da percepção do autor, passamos para a percepção de seus próprios personagens.

Ningen Shikkaku (1948), último livro completado por Dazai, é considerado por muitos críticos como uma espécie de testamento do autor, pois traz vários episódios que fazem parte de sua biografia: a infância em uma família abastada no nordeste do Japão, a vinda a Tóquio para prosseguir os estudos, a tentativa de duplo suicídio atirando-se ao mar em Kamakura com a garçonete de um bar, o vício em drogas e tratamento posterior. De fato, muitos elementos estão associados às experiências do autor, mas, como escrevemos anteriormente, não se trata de uma biografia, trata-se de um texto literário com valor próprio e não devemos transformar Ôba Yôzô em Dazai Osamu, aquilo que este último viveu e sentiu lhe pertence e permanecerá para sempre inacessível para nós, aquilo que Yôzô escreve em seus diários só pode ser atribuído a este como personagem criado por Dazai e não identificado com o próprio autor. E, nesse sentido, tudo o que Yôzô diz é real no contexto do romance, a realidade é tal como Yôzô a percebe.

8. Dazai, Osamu. Geijutsu Girai. In: Dazai Osamu Zenshû. Tóquio: Chikuma Bunko, 1989. p. 5. Disponível no site: www.aozora.gr.jp. Os números das páginas correspondem àqueles da versão em e-book disponível para download nesse site. A tradução dos textos em japonês é nossa. 
Dazai dá voz a personagens que falam sem floreios, sem enfeitar ou modificar o que sentem e, por isso, dão a impressão de espontaneidade, de que são reais. Elas se contradizem e têm a liberdade de voltar atrás quando dizem algo que consideram incorreto. A forma de diários, cartas, enfim, textos escritos em primeira pessoa, frequentes em suas obras, reforçam a sensação de proximidade com o leitor. Há uma pessoa à nossa frente que nos conta algo.

Não é possível falar em uma realidade objetiva nesses casos, pois elas são sentidas, subjetivas. Assim, é preciso falar em realidades, no plural. E Dazai sabe brincar com isso, em Ningen Shikkaku, aquilo que Yôzô diz sobre si mesmo é contradito por outros personagens. Ele se considera um pária da sociedade, bebe, fica viciado em morfina e revela vários momentos de fraqueza e covardia, no entanto, as pessoas que o conheceram defendem-no. Dizem que ele é uma boa pessoa, como a Madame o faz no epílogo, quando o narrador misterioso, o mesmo que introduz os diários de Yôzô no prólogo do livro, revela como eles chegaram a suas mãos. Ele vai até Funabashi em busca de um amigo com quem deve acertar os detalhes do casamento de um membro da família e, sem conseguir encontrar sua casa, acaba entrando em um café onde encontra uma mulher que possuía um bar em Ginza, uma antiga conhecida, a quem se refere como "Madame". Ambos conversam sobre o passado e ela lhe oferece fotos e três diários escritos por Yôzô, seu antigo freguês e amante, para que o narrador os use como material para um romance. No início, o narrador reluta em aceitar a oferta, mas acaba por lê-los. Seus comentários não são favoráveis, mas a Madame tem boas lembranças de Yôzô.

- Se tudo o que estiver escrito aqui fosse verdade, e se eu fosse amigo de Yôzô, provavelmente também iria interná-lo em um hospício.

- A culpa é do pai dele, disse a Madame com indiferença. O Yôzô que conheci era muito bondoso, sensível, se não bebesse, não, mesmo quando bebia... era um anjo. ${ }^{9}$

(Dazai, 1985, p. 193).

Em outro episódio. Yôzô ouve o seguinte diálogo entre Shizuko, mulher com quem vivia então, e a filha de cinco anos:

- Por que ele bebe?

- O tio não bebe porque gosta de beber, é porque ele é uma pessoa muito boa...

- As pessoas boas bebem?

- Não é por isso...

(Dazai, 1985, p. 130)

9. Dazai, Osamu. Ningen Shikkaku. Tóquio: Shinchôsha, 1985. p. 193. Disponível no site: www.aozora.gr.jp 
Como no caso de Dom Quixote e Sancho quando veem os moinhos, não é possível dizer que a Madame e Shizuko estejam erradas porque contradizem a imagem que o protagonista tem de si mesmo.

Qual o Yôzô real?

Todos: o bom, o "anjo", o mentiroso, o covarde.

Dazai diverte-se com a própria ideia, comum para os defensores do watakushi shôsetsu, de que texto e realidade poderiam ser confundidos. Em Haji (1942), um pequeno conto constituído de cartas escritas por uma jovem de vinte e três anos chamada Kazuko para a amiga Kikuko nas quais a primeira narra a grande humilhação que sua correspondência com um escritor chamado Toda lhe causou.

Toda é um escritor de meia-idade cujos livros, segundo Kazuko, não são populares entre as mulheres porque ele escreve sobre suas misérias, egoísmo, brigas com a esposa, além de contar que é feio, vive em um lugar sujo, tem inúmeras dívidas, bebe e dorme no chão, assuntos bem pouco atrativos para o sexo feminino e que despertam apenas desprezo, qualquer mulher teria vergonha de ser vista lendo seus livros, ela própria os lia escondida para não ser alvo de escárnio dos conhecidos.

Kazuko se dirige a Toda empregando o pronome kika ${ }^{10}$, usado para pessoas de mesmo nível social ou inferiores, explicando que anata seria estranho, pois havia a diferença de idade e não queria que Toda tivesse ideias inapropriadas em relação a ela; sensei também não parecia adequado porque ela não o respeitava tanto assim e o próprio autor se definia como uma pessoa "iletrada". O tom da primeira carta dirigida a Toda é condescendente, Kazuko escreve que, apesar de todos os seus defeitos, seus textos contêm algo que provoca empatia e pede que ele se cultive, estude mais e corrija seu comportamento para que a qualidade de seus textos melhore. Quando isso ocorresse, ela gostaria de encontrá-lo, mas, no momento, ela preferia permanecer anônima. Também sublinha que ela não é sua fã e pede que ele não mostre a carta para a esposa dizendo algo parecido.

Para Kikuko, a amiga, ela explica seu desejo de não revelar nome e endereço dando as seguintes razões:

... não escrevi meu endereço e nome nessa carta. Não é de dar medo? Se ele aparecesse todo sujo e bêbado em casa, mamãe ficaria assustada. Ele poderia ameaçá-la pedindo dinheiro emprestado, é impossível saber o que uma pessoa com maus hábitos como ele poderia fazer. ${ }^{11}$ (Dazai, 1988, p. 6-7).

10. 貴下

11. Dazai, Osamu. Haji. In: Dazai Osamu Zenshû 4. Tóquio: Chikuma Bunko, 1988. p. 6-7. Disponível no site: www.aozora.gr.jp 
Algo divertido, pois a descrição acima lembra aqueles personagens das obras de Dazai que os leitores identificam como sendo alter egos do próprio autor, sujeitos beberrões, endividados e mulherengos.

Um mês após o envio da carta a Toda, Kazuko lê o último conto do escritor publicado em uma revista literária e fica chocada, pois a protagonista tem o mesmo nome e a mesma idade que ela e também é filha de um professor universitário. Ela acaba enviando uma nova carta para Toda na qual expressa sua surpresa, pois acredita ser o modelo para a personagem, e pergunta como ele conseguiu descobrir sua verdadeira identidade, se mostrou a carta para os conhecidos, fez investigações, etc. Como ela acredita que não há mais motivo para esconder nada, acaba revelando seu endereço. Cinco dias depois, Toda responde:

Saudações. Recebi sua carta. Muito obrigado pelo apoio. Também li sua última carta. Até hoje, nunca fiz algo tão inapropriado quanto rir e mostrar uma carta para minha esposa. Também jamais fiz alarde e mostrei cartas para conhecidos. Fique tranquila em relação a isso. Você escreve que consentirá em que nos encontremos quando meu caráter melhorar, mas, afinal, o ser humano é capaz de melhorar seu próprio caráter? Cordialmente. (Dazai, 1988, p. 11)

Após ler essa carta, Kazuko sente um grande desejo de visitar Toda e se prepara para tanto. Com a intenção de não ofender o orgulho de um escritor pobre, que só tem uma peça de roupa para vestir e vive em uma casa com tatames furados cobertos com jornais, antes de sair, ela veste uma saia cheia de remendos e uma blusa amarela que ficou curta e cujas mangas quase chegam aos cotovelos. Como ele parecia sofrer de beribéri, ela decide levar um de seus cobertores usados de presente. Dentro do trem, ainda retira uma prótese dos dentes da frente e desarruma os cabelos. Ela não quer que Toda se sinta desconfortável, por meio de seus textos, ela sabe que ele perdeu vários dentes e tem má aparência.

Sua primeira surpresa é descobrir que a casa do escritor é muito diferente do que imaginara, ela é pequena, mas arrumada, e possui um jardim bem cuidado. Kazuko é recebida pela esposa do escritor, uma mulher elegante que a conduz até uma sala onde o marido está sentado diante de uma mesa. Não há nada de sujo ou feio em seu interior, está tudo muito limpo e Toda não é banguela nem está desleixado. Seu desconcerto é enorme, mas ela procura estabelecer um diálogo:

- Como o senhor sabia quem eu era? Vim para perguntar-lhe isso, disse procurando salvar as aparências.

- Como assim? Ele não tinha a menor ideia do que eu estava falando.

- Eu não revelei meu nome ou endereço, mas o senhor não os descobriu? Quando enviei a última carta, achei que minha pergunta tivesse ficado clara. 
- Eu não sei nada sobre você. Que coisa esquisita! Ele observou meu rosto com os olhos serenos sem qualquer reserva e deu uma pequena risada.

- Mas... Comecei a ficar confusa. Então o senhor não compreendeu minha última carta e ainda assim ficou quieto, isso é terrível! O senhor deve ter achado que eu era uma idiota! (Dazai, 1988, p. 15-16)

Toda explica que ele nunca faz uso de modelos em seus textos e que é tudo ficção. Kazuko se dá conta de seu engano e fica embaraçada. Ela está ali, vestida como uma mendiga, sem um dos dentes da frente, com os cabelos desgrenhados e Toda é o contrário de tudo o que inferira lendo seus textos; não é pobre, não é feio, tem boa saúde, é ilustrado e parece ter um bom relacionamento com a esposa. Kazuko sente-se traída, e volta para casa chorando, abraçada ao embrulho com o cobertor que pretendia dar de presente para Toda. Ela descreve seus sentimentos para Kikuko:

Escritores, eles não valem nada. São a escória. Só escrevem mentiras. Não são nem um pouco românticos. Vivem tranquilos em uma casa comum e desdenham uma garota mal vestida, sem os dentes da frente, não a acompanham até a porta e ficam com cara de que não estão nem aí, são horríveis. Pessoas assim não são chamadas de charlatãs? (Dazai, 1988, p. 19)

Conclusão hilária. O texto é um bom exemplo da ironia dazainiana, ele se diverte com os leitores e defensores do watakushi shôsetsu que acreditam que tudo o que está escrito nas obras de um autor deva ser tomado ao pé da letra. A realidade nos textos não deve ser confundida com o que ocorre fora dele. Ela é muito mais complexa do que sugerem as teorias.

\section{Bibliografia consultada:}

DAZAI, Osamu. Geijutsu Girai (Detesto arte). In: Dazai Osamu Zenshû. Tóquio: Chikuma Bunko, 1989. Disponível para download em: http://www.aozora.gr.jp/cards/000035/ card1600.html. Acesso em: 08 de out. 2013.

DAZAI, Osamu. Haji (Vergonha). In: Dazai Osamu Zenshû 4. Tóquio: Chikuma Bunko, 1988. Disponível para download em: http://www.aozora.gr.jp/cards/000035/card262.html. Acesso em: 08 de out. 2013.

DAZAI, Osamu. Ningen Shikkaku (Desqualificado como ser humano). Tóquio: Shinchôsha, 1985. Disponível para download em: http://www.aozora.gr.jp/cards/000035/card301. html. Acesso em: 08 de out. 2013.

FOWLER, Edward. The Rhetoric of Confession (A Retórica da Confissão). 1a ed. Berkeley: University of California Press, 1988. 
KOYANO, Ton. Watakushi Shôsetsu Towa (O que é Narrativa do Eu) $1^{\text {a }}$ ed. Tóquio: Heibonsha, 2009.

Suzuki, Tomi. Narrating the Self (Narrando o Eu). $1^{\text {a }}$ ed. Stanford: Stanford University Press, 1996. 